\title{
Input and uptake at 7 months predicts toddler vocabulary: the role of child-directed speech and infant processing skills in language development
}

\author{
ROCHELLE S. NEWMAN* \\ University of Maryland, USA \\ MEREDITH L. ROWE \\ Harvard University, USA
}

A ND

NAN BERNSTEIN RATNER

University of Maryland, USA

(Received 6 October 2014-Revised I 5 Fune 20I5-Accepted 3 August 2015-

First published online 24 August 2OI5)

\section{ABSTRACT}

Both the input directed to the child, and the child's ability to process that input, are likely to impact the child's language acquisition. We explore how these factors inter-relate by tracking the relationships among: (a) lexical properties of maternal child-directed speech to prelinguistic (7month-old) infants ( $\mathrm{N}=\mathrm{I} 2 \mathrm{I})$; (b) these infants' abilities to segment lexical targets from conversational child-directed utterances in an experimental paradigm; and (c) the children's vocabulary outcomes at age 2;0. Both repetitiveness in maternal input and the child's speech segmentation skills at age 0;7 predicted language outcomes at 2;0; moreover, while these factors were somewhat inter-related, they each had independent effects on toddler vocabulary skill, and there was no interaction between the two.

\section{INTRODUCTION}

A great deal of research (summarized briefly below) has explored how the amount/nature of child-directed speech (CDS) might influence children's

[*] Address for correspondence: University of Maryland - Hearing and Speech, o I oo Lefrak Hall, College Park Maryland 20742, United States. e-mail: rnewman I@umd.edu 
language outcomes. Other work has looked at the abilities that young infants bring to the table, such as the extensively studied ability to bootstrap language characteristics by locating individual words in fluent speech (also known as segmentation). These skills may themselves be impacted by the input to the child. But with few exceptions (e.g. Hurtado, Marchman \& Fernald, 2008; Weisleder \& Fernald, 2013), investigations of infant skills and of the input children receive have been studied separately, without asking how their respective contributions might interact to influence children's vocabulary acquisition.

In this paper, we track the relationships among the lexical properties of CDS to a large sample $(\mathrm{N}=\mathrm{I2} \mathrm{I})$ of prelinguistic (7-month-old) infants, infant segmentation skill (or the ability to separate and identify those lexical items), and the children's vocabulary outcomes at age 2;0. We first discuss what is currently known about the impacts of CDS on children's language development. We then review what is known about infant speech processing skills, particularly segmentation, and its potential role in predicting children's later language abilities. Finally, we discuss a small body of recent research that reports interactions between children's linguistic experience and speech processing abilities before presenting the current investigation and its findings.

\section{CDS and children's language learning}

Adults speak differently to language-learning children than to more mature listeners (see Bernstein Ratner, 2013; Soderstrom, 2007, for summaries); they also 'fine-tune' these speech adjustments to the child's perceived comprehension abilities (see Snow, I995, for discussion). There are documented changes in infants' preferences for input (e.g. Hayashi, Tamekawa \& Kiritani, 200I; McRoberts, McDonough \& Lakusta, 2009), suggesting possible synergies between infant preferences, adult language modification, and benefits to child language learning. However, the long-term effect of variability in CDS on later communication outcomes is less evident.

Studies of the effect of CDS have explored a number of properties, ranging from phonetic properties (such as vowel space; Liu, Kuhl \& Tsao, 2003), through grammatical components (e.g. Ambridge, Rowland, Theakston \& Kidd, 20I5), and pragmatic features (e.g. Hirsh-Pasek et al., 2015; Tamis-LeMonda, Bornstein \& Baumwell, 200I; Tomasello \& Farrar, I986). In the present paper, we focus particularly on characteristics at the lexical level, as that level is one where children's own processing skills can be easily explored at the same age as parental input. Research suggests that input registers characterized by more verbosity and diversity appear to facilitate vocabulary development in toddlers and preschoolers. 
For example, Hoff and Naigles (2002) found that quantity of speech and lexical diversity predicted lexical achievement in two-year-old children $(\mathrm{N}=63)$. Diversity of CDS vocabulary has been linked to outcomes at age two and beyond in middle-class families (Bornstein, Haynes \& Painter, I 998; Hart \& Risley, I995; Hoff-Ginsberg, I99ı; Huttenlocher, Haight, Bryk, Seltzer \& Lyons, I99r) and lower SES families (Pan, Rowe, Singer \& Snow, 2005; Shimpi, Fedewa \& Hans, 2012). Increases in the number of child-directed words (tokens in the input) as well as types (unique words) and rare / less common words correlate with higher levels of child vocabulary (Rowe, 20I2; Weizman \& Snow, 200I). However, few studies have investigated CDS to infants under I 4 months, or specific aspects of input that may be beneficial at this early age.

Although there is a general sense that more language input and thus more words leads to better language outcomes, different features of CDS may play a larger or smaller role at different points in development. Furrow, Nelson, and Benedict ( 1979) argued that "what leads to a change in the system at one point in development may be completely ineffective at another point", and Bohannon and Leubecker (I988) cautioned that CDS consists of "reciprocal, non-linear relations". While input quantity is clearly important, other specific features of input are helpful over and above quantity, and the more we understand about these helpful features of input the more we can learn about the mechanisms involved in language learning (e.g. Rowe, 2012, 2015). Conceivably, while 'more words' in the input may generally be important, early in the first year of life repetition of words may be particularly useful, whereas lexical diversity is linguistically enriching later on. Indeed, McRoberts et al. (2009) reported that 6-month-old infants show preference for repeated, as opposed to novel, utterances. It also could be important how often parents provide their children with input that does not require segmentation to identify the words (e.g. I-word utterances); Brent and Siskind (200I) reported that exposure to a word in one-word utterances predicted the likelihood that the child would later use that word productively.

\section{The role of processing in language learning}

Most CDS studies have not tracked children's concurrent speech processing skills. A notable exception is Hurtado et al. (2008), who tracked twenty-seven children between the ages of $1 ; 6$ and 2;0; those whose mothers provided richer input at I;6 (as estimated by automated counts of mothers' CDS by the LENA software system) had higher vocabulary scores and faster word recognition at 2;0. The authors concluded that enriched input influences lexical processing efficiency and that such improvements can work synergistically to advantage children. The team 
extended findings to twenty-nine Spanish-learning infants studied between ages I;7 and 2;0 (Weisleder \& Fernald, 20I3). Richer input at I;7 (again, as estimated by CDS words recorded by LENA) predicted children's vocabulary at age 2;0, and the speed with which the toddlers oriented to images when presented with a word in the laboratory. Thus, maternal input spurred vocabulary learning, and also led to improved capacity to attend to and process incoming speech information, which in turn was independently associated with better vocabulary outcomes.

Most CDS consists of multiword utterances (e.g. Aslin, Woodward, LaMendola \& Bever, I996) without obvious signals demarcating word boundaries. Infants must somehow subdivide utterances into individual units (word segmentation). Early segmentation investigations familiarized infants with isolated monosyllabic target words (Jusczyk \& Aslin, 1995). Infants were then tested on their ability to recognize these same words in fluent speech stimuli. At 0;7・I 5 (but not o;6, at least for English), infants demonstrated ability to segment words from fluent speech (see also Jusczyk, Houston \& Newsome, I999). Segmentation shows a gradual developmental timecourse, and infants appear to use a variety of cues to segment (Jusczyk, I 999, and subsequent work). Thus, there is individual variability; similar-aged children may differ in abilities or strategies. For example, of twenty-four infants in the first experiment of the Jusczyk et al. ( I999) study, only eighteen showed segmentation skill-in short, children regularly show non-uniform performance patterns.

Does failure to perform well in a laboratory-based segmentation or similar speech perception task have implications for later language development? Failure should presumably delay vocabulary acquisition, and a recent meta-analysis documents that infant speech perception performance predicts later language skill equally as well as non-linguistic measures, such as habituation/dishabituation and/or rapid auditory processing tasks (Cristia, Seidl, Junge, Soderstrom \& Hagoort, 2014). Segmentation abilities are delayed in children with cognitive/linguistic deficits (Nazzi, Paterson \& Karmiloff-Smith, 2003), in line with the notion that segmentation could be a necessary precursor for typical language development. A retrospective analysis found that typically developing infants aged $0 ; 7-0 ; 8$ who fail laboratory segmentation tasks have significantly poorer age 2;0 language outcomes than do successful infants (Newman, Bernstein Ratner, Jusczyk, Jusczyk \& Dow, 2006). Further, at age $4 ; 0-6 ; 0$, those children who had failed laboratory segmentation tasks as infants demonstrated lower syntactic and semantic skills, but did not differ in general intellectual abilities, suggesting that infant segmentation may specifically predict language development. Singh, Reznick, and Xuehua (2012) recently extended this finding. They prospectively correlated children's laboratory performance (on both simple and complex 
segmentation tasks) at $0 ; 7 \cdot I_{5}$ and their vocabulary outcomes at 2;0. Similarly, Junge and colleagues (e.g. Junge, Kooijman, Hagoort \& Cutler, 20I2) reported that infants with more advanced ERP patterns at o;7 had larger language quotients at 3;0 and larger receptive vocabularies at 2;0. Thus, infants' failure on laboratory segmentation tasks may signal a language-processing developmental lag, rather than transient inattention during testing (see Cristia et al., 2014, for more extensive discussion).

\section{The current study}

Children's ability to segment CDS may predict later language outcomes. Similarly, the quantity of CDS available to be segmented (Bornstein et al., I998; Hart \& Risley, I995; Huttenlocher et al., I991) and lexical properties such as vocabulary diversity (Hoff, 2003; Pan et al., 2005; Rowe, 20I2) lead to differential outcomes in language development. Yet no work to date has explored both lexical input and segmentation ability within the same cohort, as Cristia et al. (2014) observe. We evaluate how these factors relate to one another and jointly predict later language skills, using a much larger cohort of children than in prior studies.

Specifically, our goals were:

I. To replicate findings that segmentation ability at $0 ; 7$ positively predicts vocabulary at 2;0;

2. To examine whether lexical aspects of maternal input at o;7 predict child vocabulary at $2 ; 0$;

3. To determine whether segmentation ability and input simultaneously predict child vocabulary at age 2;0 and whether there is interaction between the two predictors.

\section{METHODS}

\section{Participants}

One hundred and twenty-one mother-child ( 58 male) dyads participated in a longitudinal project with multiple visits across a two-year span (initial goal had been I20 completed participants). Our sampling strategy and summary of attrition is described in Table $\mathrm{I}$. One hundred and seventy-three families were initially tested, but twenty-eight were excluded prior to one year of age because of family move or request for removal $(n=25)$; genetic disorder or health issues $(n=2)$; or only the father being free to participate $(n=I)$. Data from an additional ten participants were removed either because the child was not learning English as the majority language at some point during the study (some children began hearing English the majority of the time but their language exposure changed over the course of the study) or because the mother was not a native speaker of 


\begin{tabular}{|c|c|c|}
\hline Participant group & $\begin{array}{l}\text { Number } \\
\text { of dyads }\end{array}$ & Reason for exclusion \\
\hline Initially tested at 7.5 months & I73 & \\
\hline $\begin{array}{l}\text { Participants who were still } \\
\text { enrolled at one year of age }\end{array}$ & I4 I & $\begin{array}{l}\text { genetic disorder or health reasons }(n=2) \text {; only } \\
\text { father could attend }(n=1) \text {; moved out of area or } \\
\text { did not return after first visit }(n=25) \text {; mother } \\
\text { non-native speaker or child not majority } \\
\text { English }(n=4)\end{array}$ \\
\hline $\begin{array}{l}\text { Dyads who returned for final } \\
\text { visit }\end{array}$ & I 2 I & $\begin{array}{l}\text { Could not schedule final visit }(n=13) \text {; identified } \\
\text { with a language disorder prior to } 2 ; 0(n=1) \text {; } \\
\text { language percentage at end of study }(n=6)\end{array}$ \\
\hline Included in final analyses & II 7 & $\begin{array}{l}\text { Incomplete MCDI data }(n=1) ; \text { MCDI of less } \\
\text { than } 50 \text { words }(n=3)\end{array}$ \\
\hline $\begin{array}{l}\text { Included in maternal speech } \\
\text { analyses }\end{array}$ & I I 5 & Missing audio file of maternal speech $(n=2)$ \\
\hline $\begin{array}{l}\text { Included in segmentation } \\
\text { analyses }\end{array}$ & 96 & $\begin{array}{l}\text { Fussed out of laboratory task }(n=15) \text {; refused to } \\
\text { look towards the flashing lights }(n=3) \text {; } \\
\text { equipment failure }(n=3)\end{array}$ \\
\hline Included in combined analyses & 94 & (combination of exclusions above) \\
\hline
\end{tabular}

English. Finally, an additional fourteen children were later excluded because they failed to attend the final visit $\left(n=I_{3}\right)$ or had been identified with a language disorder during their second year $(\mathrm{n}=\mathrm{I})$, leaving I2 I participants.

Mothers averaged I $7 \cdot$ I years of education (range: HS diploma to PhD.); fathers had 17.0 years. Ethnicity was 79\% Caucasian, I2\% AfricanAmerican, 4\% Hispanic, 2.5\% Asian, and 2.5\% Native-American/PacificIslander. Age at first visit ranged from $0 ; 6 \cdot 28$ to $0 ; 8 \cdot 8$ (average $7 \cdot 49$ months). Age at the two-year visit ranged from I;II.I to $2 ; 2 \cdot 6$ (average 24.3 months). Numbers of participants vary slightly across analyses as noted, due to sporadic incomplete data (e.g. audios of maternal input were distorted/uncodable for 2 participants, etc.).

Dyads participated in a range of tasks at multiple ages designed to address a variety of theoretical questions; the current paper explores those measures specifically focused on segmentation, maternal input, and vocabulary outcomes.

\section{Segmentation task, age 0;7.I 5}

The task was modeled after Jusczyk and Aslin (1995). Infants sat on their caregiver's lap in a three-sided test booth. An experimenter hidden behind the booth pressed a button on a response box to indicate direction of the child's looking behavior. At trial start, a center light in the front panel flashed. When the child responded, it was extinguished and a side panel light began to flash. Once the child looked towards that light, a sound file 
played from a hidden loudspeaker, continuing until the child looked away for two consecutive seconds, at which point the next trial began. Total amount of looking time to the flashing light was calculated as a measure of listening time; any time the infant spent looking away (2 s or less) was excluded.

There were familiarization and test phases. During familiarization, children heard repetitions of two words (bike and feet) on different trials, until they accumulated a total of $30 \mathrm{~s}$ of listening time to each word. During test phases, children heard sixteen trials (4 blocks of 4 trials). In each trial, children heard a six-sentence passage focused on one of four target words: bike, feet, cup, and goat (e.g. "The goat pranced across the field. He saw a really big goat. He patted his goat on the back."; we used goat rather than $d o g$, as Jusczyk and Aslin did, because $d o g$ engenders extreme preferences in some infants, unlike other words in the set, a concern for an individual-difference study; in addition, our location on a dialectal border could affect family production of that vowel in particular). Each block contained one trial for each passage, in random order. Average listening time to passages containing the two novel words was compared to trials containing familiarized words. Data were analyzed from all participants who completed at least three of the four blocks without fussing out (I02 of I2I children). The experimenter and caregiver wore Peltor Aviation headphones playing masking music to block hearing the stimuli and biasing the child's behavior or subsequent coding.

\section{Input assessment, age 0;7.I5}

After the segmentation task, dyads played with a standard set of toys, including plush animals, baby doll with accessories, food-/eating-/ cooking-related items, and board books. Mothers were asked to play with their children as they would normally at home. They were informed that they were being video- and audio-recorded, and asked to wear an Audio-Technica AT 853 I lavalier microphone connected to a Marantz PMD 660 solid-state digital recorder; mothers were told that while our intent was to record the child, they should wear the microphone so that their child would not play with it. Sessions lasted approximately I 5 minutes. All recordings were transcribed via sonic CHAT mode using TalkBank utilities (MacWhinney, 2000). Transcripts were analyzed using CLAN for total amount of input (tokens), vocabulary diversity (types), and repetitiveness of the input (type-token ratio, or TTR), and for the percentage of utterances that were a single word in length.

\section{Vocabulary assessment, age 2;0}

Children returned at approximately two years of age. At this visit, parents completed the MacArthur-Bates Communicative Development Inventory I 64 
(Fenson et al., I993). Children's vocabulary scores on the MCDI at age 2;0 varied widely. Three children had scores below 50 words, suggesting possible clinically relevant delay and were excluded from further analyses; MCDI scores were unavailable for one additional child, resulting in a final sample of $\mathrm{n}=\mathrm{i}$ i 7 . Mean MCDI score was $324 \cdot 2\left(\mathrm{SD}=\mathrm{I}_{57 \cdot 7}\right.$, range $=62-$ 664), comparable to original norming study scores (Fenson, Dale, Reznick, Bates, Thal \& Pethick, I994; mean = 3 I 2 words, SD= I74). MCDI scores were normally distributed in this sample.

\section{RESULTS}

We first sought to replicate our previous retrospective finding (Newman et al., 2006) that infants' ability to segment fluent speech predicted later vocabulary skill. Of the I 77 participants with usable MCDI scores, 2 I did not complete the laboratory task (fussed out $\left(n=I_{5}\right)$, refused to look towards the flashing lights $(n=3)$, or equipment failure $(n=3))$. Thus, 96 participants were available for analysis; looking time was normally distributed. The earlier study split children into two groups based on vocabulary, looking only at the top and bottom i $5 \%$; however, we had a smaller sample, and thus included all children, splitting into two equivalent groups. We compared children with higher (MCDI > 300) and lower $(\mathrm{MCDI}<300)$ vocabulary scores. Children in the upper-MCDI group showed a greater novelty preference on the segmentation task than children in the lower-MCDI group $(t(95)=2 \cdot 24, p<.05)$, thus replicating our previous finding of a relationship between segmentation and later outcomes. (Correlations across MCDI scores showed a similar relationship: $r(95)=0.25, p<.02)$ However, the direction of this relationship was different from the previous study: we found that novelty, not familiarity, preferences led to larger vocabulary scores, a point we return to in the 'Discussion'.

We next asked whether maternal input at child age $0 ; 7 \cdot$ I 5 predicts MCDI scores at 2;0. Maternal input was unavailable for two dyads due to poor recordings; thus, this analysis included II5/II7 families with usable MCDI scores (we included children who did not complete the segmentation task successfully). CLAN was used to compute maternal tokens, types, and TTR in 7-month-directed CDS, and the percentage of utterances that were a single word in length. Maternal tokens ranged from 75 to $5_{566}(\mathrm{M}=758 \cdot 8)$. Maternal types ranged from 39 to $392(\mathrm{M}=$ $22 \mathrm{I} \cdot 8)$. Maternal TTR ranged from $0 . \mathrm{I} 8$ to $0.62(\mathrm{M}=0.32 \mathrm{I})$. Lower TTR indicates more repetition. Mothers varied in the percentage of one-word utterances from 0.03 to $0.48(\mathrm{M}=0.20)$. All four of the input measures were normally distributed and did not require transformation. Children's two-year MCDI scores were significantly positively correlated with 
mothers' tokens $(r=0.23)$ and types $(r=0.20)$, and significantly negatively correlated with TTR $(r=-0 \cdot 28)$. That is, children's vocabulary scores were higher if their mother produced more words, and more different words, but also if their mothers used more repetition. Children's two-year MCDI scores did not correlate significantly with the percentage of one-word utterances that mothers used $(r=-0.08)$. TTR had the strongest association with the MCDI scores, thus we opted to use TTR as the input measure for further analysis. Unsurprisingly, maternal tokens, types, and TTR are all significantly inter-correlated. Interestingly, controlling for types, the relation between TTR and MCDI is still significant $(r=-0 \cdot 20$, $p<.05)$, but when controlling for tokens, it is not $\left(r=-0 \cdot \mathrm{I}_{5}, p=\cdot_{\mathrm{I}} \mathrm{I}\right)$.

Are infants' abilities to segment speech at $0 ; 7 \cdot \mathbf{I}_{5}$ and maternal repetitiveness at that same age related? Segmentation ability might already, even at this early age, be affected by the input children receive. The two measures marginally correlate $(r(92)=0.19, p<.10)$; thus, in this sample, there is a tendency for infants showing a novelty preference on segmentation tasks to hear more repetition from mothers. We return to this finding when we model the relationship among these variables and child language outcomes.

We last asked whether child segmentation ability and maternal input, when considered simultaneously, explain unique variation in child vocabulary at age 2;0. We conducted multiple regression analyses using infant novelty preference and maternal input (TTR) as predictors of children's MCDI scores (all as continuous measures) at age 2;0 (see Table 2). Although it is unclear whether segmentation results from a study using the head-turn preference procedure task should be measured continuously (looking time) or categorically (looking longer to the appropriate item vs. not doing so), this choice does not change the pattern of results. Data include the ninety-four participants having segmentation, TTR, and MCDI data available. Model I (Table 2) shows the independent significant effect of child segmentation ability at $0 ; 7 \cdot \mathbf{I}_{5}$ on MCDI scores at age two. In this model, infants' segmentation ability explains $6 \cdot \mathbf{I} \%$ of variation in toddler vocabulary skills. Model 2 presents the independent significant effect of maternal repetitiveness at $0 ; 7 \cdot I_{5}$ on child MCDI scores at age two. In this model, maternal input at $0 ; 7 \cdot \mathbf{I}_{5}$ explains $7 \cdot 0 \%$ of the variation in two-year-old child vocabulary. Model 3 includes both infant segmentation ability and maternal input as simultaneous predictors. In this model, both predictors remain significant and the amount of variation explained increases to nearly i $1 \%$. Thus, when considered together, both child segmentation ability and parent repetitiveness at child age 0;7.I5 are significantly related to children's vocabulary skill at 2;0, as measured on the MCDI. A change in R-square statistic was calculated to determine whether Model 3 was a significantly better fitting model than Models I or 2, despite 
TABLE 2. Regression models predicting child vocabulary production at age two (MCDI) based on infant segmenting ability and maternal input at age $7 \cdot 5$ months $(n=95)$

\begin{tabular}{lcccc}
\hline & \multicolumn{4}{c}{ MCDI scores at age two } \\
\cline { 2 - 5 } & \multicolumn{4}{c}{$\beta$-coefficient (standard error) } \\
\cline { 2 - 5 } Predictors & Model I & Model 2 & Model 3 & Model 4 \\
\hline Intercept & $3 \mathrm{II} \cdot 67^{* *}$ & $484 \cdot 85^{* *}$ & $460 \cdot 96^{* *}$ & $457 \cdot 78^{* * *}$ \\
& $(\mathrm{I} 6 \cdot 24)$ & $(68 \cdot 9 \mathrm{I})$ & $(68 \cdot 83)$ & $(69 \cdot 39)$ \\
Infant segmenting & $\mathrm{I} 6 \cdot 04^{*}$ & & $\mathrm{I} 3 \cdot 20^{*}$ & $-\mathrm{I} \cdot \mathrm{I} 0$ \\
& $(6 \cdot 58)$ & & $(6 \cdot 57)$ & $(28 \cdot 6 \mathrm{I})$ \\
Maternal input & & $-549 \cdot 20^{* *}$ & $-467 \cdot 30^{*}$ & $-452 \cdot 73^{*}$ \\
Segmenting x input interaction & & $(208 \cdot 99)$ & $(209 \cdot 62)$ & $(2 \mathrm{I} 2 \cdot 37)$ \\
& & & & $42 \cdot 96$ \\
R-squared stat (\%) & $6 \cdot \mathrm{I}$ & $7 \cdot 0$ & $\mathrm{IO} \cdot 9$ & $(83.65)$ \\
\hline
\end{tabular}

NOTES: $* p<.05 ; * * p<.0 \mathrm{I}$.

the inclusion of an additional predictor. The comparisons resulted in Partial $\mathrm{F}$ statistics of 4.96 (Model 3 vs. I) and 4.03 (Model 3 vs. 2), which are both greater than the corresponding alpha $=.05$ critical $F$-value of 3.95 . Thus, Model 3, which contains the effects of both infant segmenting and maternal input, is a significantly better fitting model than Model I or 2. In Model 4, we added the interaction term between segmentation ability and input to determine whether the effect of input differed based on segmentation ability. The interaction was non-significant. As a final step, not shown in the table, we considered potentially important control variables. Neither parent education (fairly homogenous in this sample), nor child gender related to MCDI scores at age 2;0, with TTR and segmentation ability in the model, and thus were not retained in the analysis. We also examined the joint impact of the percentage of one-word utterances and segmentation ability, and their interaction, on vocabulary outcomes, in case the percentage of one-word utterances was particularly important in children whose segmentation skills were weak, but found no relationships. Thus, our final model is Model 3, suggesting that both infant skills (segmenting) and repetitiveness in the input (TTR) at $0 ; 7 \cdot 15$ contribute to children's later productive vocabulary size. Residuals from this model were examined and did not violate any of the regression assumptions.

\section{DISCUSSION}

Most children acquire their native language successfully and rapidly over a very short time frame in the first years of life. But some children do not 
acquire language as well as others, and we are as yet unable to predict which children will be more or less successful language learners. We examined the potential contributing roles of two factors at age o; $\bullet^{\prime}$ 5: (i) infants' ability to break up fluent speech into individual words (segmentation); and (ii) the input that children hear from their mothers. Each has been argued to be a critical underpinning for language acquisition; however, most work on the role of input investigates $\mathrm{CDS}$ to children older than 0;7.15. Both maternal input (repetitiveness) and speech segmentation skills at $0 ; 7 \cdot \mathbf{I} 5$ predicted child language outcomes at 2;0; moreover, while these factors were somewhat related to one another, they each had independent effects on toddler vocabulary skill.

These results support prior retrospective and prospective work (e.g. Newman et al., 2006; Junge et al., 2012; Singh et al., 2012), suggesting that children's laboratory performance may reveal individual speech processing skills. Moreover, this ability contributed significantly to vocabulary outcome scores even once maternal input was factored in, suggesting that segmentation skills are not isomorphic with input patterns, though they may share a partially mediated relationship. Rather, this segmentation task may measure children's processing abilities, independent of their environmental exposure. Clearly, future work should explore this more fully by examining parental input prior to 0;7.I5, our earliest datapoint. Because at this age both segmentation ability and maternal input appeared to contribute independently to the child's language profile at age two, the directionality of this association is unclear. Processing skill and input style may be independent, or interact in ways currently unknown, such that maternal input style may have given our young infant participants benefits in facing segmentation task challenges, or that infants with better segmentation skills could better capitalize on a particular maternal style of input. McRoberts et al. (2009) suggest that "attention to repeated utterances precedes word segmentation and statistical cues in continuous speech". This suggests that repetition in infant-directed speech actually primes the child's ability to segment. In McRoberts et al., six-month-old children (younger than our youngest subjects) particularly showed preference for a more repetitive infant-directed signal. Further, our analyses found a marginal correlation between CDS repetitiveness and child segmentation ability. Additional longitudinal research, starting at younger ages, may enlighten the directionality of the relationship between infant segmentation ability and experience with particular profiles of CDS in their environment.

In the current study, infants who showed novelty preferences in the segmentation task showed larger later vocabularies, rather than infants who showed familiarity preferences, as suggested in our prior work. The interpretation of novelty vs. familiarity preferences in infants is a matter of 
long-standing concern (Burnham \& Dodd, I998; Houston-Price \& Nakai, 2004; Slater, 2004). Burnham and Dodd note that "From one point of view, it can be argued that the valence of the preference is unimportant, for as long as there is a preference, then discrimination is demonstrated" (p. I74). Cristia et al. (2014) briefly discuss the problem of understanding which type of preference is predictive of later outcomes, given various ages and tasks. Here, we were not testing discrimination per se, but evaluating how individual differences in the ability to make a discrimination (between familiarized and unfamiliarized words) predicted later abilities. Many factors influence whether a particular infant shows novelty vs. familiarity preferences (e.g. stimulus complexity, familiarization time). In general, children seem to show novelty preferences when they are more 'bored' with the stimulus, because it is inherently less interesting / simpler, because it has been presented more times, or because they have completed processing. This suggests that more cognitively advanced infants should be more likely to show novelty preferences, since they will process more quickly, in line with the current results (where infants showing a stronger novelty preference were more advanced in vocabulary acquisition rates). Nonetheless, the variation across studies is of concern, and may encourage the use of other paradigms in future work, such as ERPs (as in Junge et al., 2012), where such shifts over time or development are less likely to occur. That said, there were also some important differences between this study and prior work. In particular, all the children in the current experiment participated in the same segmentation task-one that focused on monosyllabic words spoken by the same talker. In contrast, the Newman et al. (2006) paper retrospectively examined a large set of children who had participated in a variety of segmentation studies, and collapsed data across these different studies. The studies themselves included ones in which the talker varied between training and test, where the words were multisyllabic, or where there was a limited set of acoustic cues available. In other words, the current study used a simpler (likely easier) segmentation task - this may help explain why novelty preference, rather than familiarity preference, was seen here.

Cristia et al. (2014) note that the infant's linguistic environment cannot be ignored in trying to link speech perception task performance and children's later linguistic skills. In the current study, both the input and the child's processing proclivities appear to work synergistically to provide benefit to the language-learning process. This may explain, in part, why, for input to aid in child language acquisition, it must be child-addressed, and not merely overheard (Shneidman \& Goldin-Meadow, 20ı 2; Weisleder \& Fernald, 2013). Our findings also confirm that input addressed to quite young infants, who show rudimentary comprehension in naturalistic conversations, and only prelinguistic levels of verbal expression, does have 
a measurable impact on the rate of language development over the first two years of life. At these early stages, it is access to repeated instances of words that appears to facilitate mapping of lexical targets.

There were no effects of either gender or parent education on children's outcomes once input and segmentation abilities were entered into the equation. Lack of an SES effect may reflect limited diversity in our sample; only eleven mothers had less than a college education, with only one without some education post-high school. The fact that profiles of interaction even within this rather privileged sample appeared to influence children's outcomes at age two is significant for its ramifications on the quality of child care (particularly adult-infant ratio) in less advantaged communities, for children under the age of one year. However, the lack of an effect of gender may be more surprising.

We also found no effect of the percentage of one-word utterances that parents used; mothers' use of single-word utterances might have been expected to interact with children's segmentation ability, in that children with weaker segmentation skills might benefit from parents who provided already segmented input. That did not appear to be the case, however. These findings also seem to contradict those of Brent and Siskind (200I), who found a relationship between mothers' use of words in isolation and children's vocabulary acquisition. However, Brent and Siskind examined the relationship between individual words being produced in isolation, and the likelihood of those particular words being learned by children; in contrast, we calculated the proportion of maternal one-word utterances overall, and related that to the size of children's productive vocabulary, without attempting to identify whether there was specific overlap among word sets.

Critically, we only explored vocabulary outcomes within typically developing children; although we identified children whose vocabulary scores satisfy a diagnosis of Specific Emergent Language Delay (a precursor to specific language impairment, or SLI), our sample included only three such children. This was not a sufficient number to explore possible predictors for this group, and thus we excluded them from our analysis. However, one direction for future work would be to explore aspects of both nature and nurture that could predict those children most at risk for later language difficulties.

In the end, our data provide further evidence for the role of the child and the role of environmental (i.e. input) effects in early vocabulary development. Both are critically important to the eventual outcome. Moreover, our finding of specific lexical input profiles linked to higher levels of vocabulary knowledge is of extreme practical importance, since vocabulary both measures and enables scholastic achievement (Snow, Burns \& Griffin, I998). It appears that the REPETITIVEnEss of the vocabulary input with 7 -month-old children is a key factor. Finding an 
association between input profiles at an early age and later language skill enables us to guide parents, caretakers, and childcare policy to maximize children's language and educational potential.

\section{ACKNOWLEDGEMENTS}

This work was supported by NSF grant BCS 07454 I 2 to the University of Maryland. The authors thank Lisa Tuit, Sean Hendricks, and Amelie Bail for conducting much of the testing of the assessments at age 2;0, and Devon Brunson, who performed most of the scheduling. We particularly thank Giovanna Morini for helpful oversight and commentary, and Kelly Hartman, Kerry McColgan, Julia Sampson, Jenna Poland, Christina Royster, and Anna Synnesvedt for coding oversight. The authors also thank the following students for assistance in recruiting and scheduling families or transcribing test sessions: Katrina Ablorh, Candace Ali, Saher Ali, Alison Arnold, Megan Askew, Catherine Bender, Taryn Bipat, Michelle Cass, Danielle Chazen, Alyssa Cook, Jennifer Coon, Sara Davis, Justine Dombroski, Sara Dougherty, Cathy Eaton, Sara Edelberg, Daniel Eisenberg, Meaghan Ervin, Lauren Evans, Andrea Farina, Josefina Fernandez, Lauren Fischer, Andrea Fisher, Arielle Gandee, Richard Garcia, Whitney Goodrich-Smith, Eliana Groskin, Natalie Hein, Laura Horowitz, Tim Howell, Megan Janssen Crenshaw, Mina Javid, Amanda Jensen, Jamie Karen, Caroline Kettl, Michelle Keenan, Esther Kim, Stephanie Lee, Perri Lieberman, Rachel Lieberman, Danielle Lindenger, Rachel Lipinski, Katie Lippitt, Debbie Martinez, Jenn McCabe, Eileen McLaughlin, Kelly McPherson, Debra Mirazhi, Vidda Moussavi, Molly Nasuta, Ashley Nimmo, Courtenay O'Connor, Sabrina Panza, Elise Perkins, Amanda Pasquarella, Lauren Polovoy, Rachel Ports, Rachel Rhodes, Allie Rodriguez, Maria Rodriguez, Judith Segal, Katie Shniderman, Veronica Son, Mara Steinberg, Sarah Steele, Justine Taweel, Allison Temple, Dena Tran, Hillary Tyler, Eugene Vassilas, Susan Veppumthara, Krista Voelmle, Chelsea Vogel, Amanda Wildman, Cavena Williams, Kimmie Wilson, Catherine Wu, Donna Zack-Williams and Michelle Zobel.

\section{REFERENCES}

Ambridge, B., Rowland, C. F., Theakston, A. L. \& Kidd, E. J. (2015). The ubiquity of frequency effects in first language acquisition. Fournal of Child Language 42(2), 239-73.

Aslin, R. N., Woodward, J. Z., LaMendola, N. P. \& Bever, T. G. (I996). Models of word segmentation in fluent maternal speech to infants. In J. L. Morgan \& K. Demuth (eds), Signal to syntax: bootstrapping from speech to grammar in early acquisition (pp. I I7-34). Mahwah, NJ: Lawrence Erlbaum.

Bernstein Ratner, N. (2013). Why talk with children matters. Seminars in Speech and Language 34, I $3 \mathrm{I}-42$. 
Bohannon, J. N. \& Leubecker, A. (1988). Recent developments in speech to children: we've come a long way, baby-talk. Language Sciences 1o, 89-ı го.

Bornstein, M. H., Haynes, M. O. \& Painter, R. M. (1998). Sources of child vocabulary competence: a multivariate model. Fournal of Child Language 25, 367-93.

Brent, M. R. \& Siskind, J. M. (200I). The role of exposure to isolated words in early vocabulary development. Cognition 8I, B33-44.

Burnham, D. \& Dodd, B. (1998). Familiarity and novelty in infant cross-language studies: factors, problems, and a possible solution. Advances in Infancy Research 12, 170-87.

Cristia, A., Seidl, A., Junge, C., Soderstrom, M., and Hagoort, P. (2014), Predicting individual variation in language from infant speech perception measures. Child Development 85, I $330-45$.

Fenson, L., Dale, P. S., Reznick, J. S., Bates, E., Thal, D. J. \& Pethick, S. J. (1 994). Variability in early communicative development. Monographs of the Society for Research in Child Development (242, Vol. 59, I-I 73).

Fenson, L., Dale, P. S., Reznick, J. S., Thal, D. J., Bates, E., Hartung, J., ... \& Reilly, J. S. (1993). The MacArthur Communicative Development Inventories: user's guide and technical manual. Baltimore, MD: Paul H. Brookes Publishing Co.

Furrow, D., Nelson, K. \& Benedict, H. (1979). Mothers' speech to children and syntactic development: some simple relationships. Fournal of Child Language 6, 423-42.

Hart, B. \& Risley, T. R. (I995). Meaningful differences in the everyday experience of young American children. Baltimore, MD: Paul H. Brookes Publishing Co.

Hayashi, A., Tamekawa, Y. \& Kiritani, S. (200I). Developmental change in auditory preference for speech stimuli in Japanese infants. Fournal of Speech and Hearing Disorders 44, I I $89-200$.

Hirsh-Pasek, K., Adamson, L. B., Bakeman, R., Owen, M. T., Golinkoff, R. M., Pace, A., ... \& Suma, K. (2015). The contribution of early communication quality to low-income children's language success. Psychological Science 26, Iо7 I-83.

Hoff, E. (2003). The specificity of environmental influence: socioeconomic status affects early vocabulary development via maternal speech. Child Development 74, г $368-78$.

Hoff, E. \& Naigles, L. (2002). How children use input to acquire a lexicon. Child Development 73, $4 \mathrm{I} 8-33$.

Hoff-Ginsberg, E. (I99I). Mother-child conversation in different social classes and communicative settings. Child Development 62, 782-96.

Houston-Price, C. \& Nakai, S. (2004). Distinguishing novelty and familiarity effects in infant preference procedures. Infant and Child Development 13, 34I-8.

Hurtado, N., Marchman, V. A. \& Fernald, A. (2008). Does input influence uptake? Links between maternal talk, processing speed and vocabulary size in Spanish-learning children. Developmental Science II, F3 I-9.

Huttenlocher, J., Haight, W., Bryk, A., Seltzer, M. \& Lyons, T. (I99r). Early vocabulary growth: relation to language input and gender. Developmental Psychology 27, 236-48.

Junge, C., Kooijman, V., Hagoort, P. \& Cutler, A. (2012). Rapid recognition at Io months as a predictor of language development. Developmental Science 15, 463-73.

Jusczyk, P. W. (1999). How infants begin to extract words from speech. Trends in Cognitive Science 3, 323-8.

Jusczyk, P. W. \& Aslin, R. N. (1995). Infants' detection of the sound patterns of words in fluent speech. Cognitive Psychology 29, I-23.

Jusczyk, P. W., Houston, D. M. \& Newsome, M. (I999). The beginnings of word segmentation in English-learning infants. Cognitive Psychology 39, I 59-207.

Liu, H.-M., Kuhl, P. \& Tsao, F.-M. (2003). An association between mothers' speech clarity and infants' speech discrimination skills. Developmental Science 6, F I-F Io.

MacWhinney, B. (2000). The CHILDES project: tools for analyzing talk, 3 rd ed. Mahwah, NJ: Lawrence Erlbaum Associates.

McRoberts, G. W., McDonough, C. \& Lakusta, L. (2009). The role of verbal repetition in the development of infant speech preferences from 4 to I 4 months of age. Infancy 14, I62-94. 
Nazzi, T., Paterson, S. \& Karmiloff-Smith, A. (2003). Early word segmentation by infants and toddlers with Williams Syndrome. Infancy 4, $25 \mathrm{I}-7 \mathrm{I}$.

Newman, R. S., Bernstein Ratner, N., Jusczyk, A. M., Jusczyk, P. W. \& Dow, K. A. (2006). Infants' early ability to segment the conversational speech signal predicts later language development: a retrospective analysis. Developmental Psychology 42, 643-55.

Pan, B., Rowe, M., Singer, J. \& Snow, C. (2005). Maternal correlates of growth in toddler vocabulary production in low income families. Child Development $\mathbf{7 6}, 766_{3}-82$.

Rowe, M. L. (2012). A longitudinal investigation of the role of quantity and quality of child-directed speech in vocabulary development. Child Development 83, i 762-74.

Rowe, M. L. (2015). Input versus intake: a commentary on Ambridge, Kidd, Rowland, and Theakson's 'The ubiquity of frequency effects in first language acquisition'. Fournal of Child Language 42, 30 I-5.

Shimpi, P. M., Fedewa, A. \& Hans, S. (2012). Social and linguistic input in low-income African American mother-child dyads from I month through 2 years: relations to vocabulary development. Applied Psycholinguistics 33, 78 I-98.

Shneidman, L. A. \& Goldin-Meadow, S. (20I2). Language input and acquisition in a Mayan village: How important is directed speech? Developmental Science 15, 659-73.

Singh, L., Reznick, J. S. \& Xuehua, L. (2012). Infant word segmentation and childhood vocabulary development: a longitudinal analysis. Developmental Science I5, 482-95.

Slater, A. (2004). Novelty, familiarity, and infant reasoning. Infant and Child Development $\mathbf{1 3}$, $353-5$.

Snow, C. E. (1995). Issues in the study of input: finetuning, universality, individual and developmental differences, and necessary causes. In P. Fletcher \& B. MacWhinney (eds), The handbook of child language (pp. I 80-93). Cambridge, MA: Blackwell.

Snow, C. E., Burns, S. \& Griffin, P. (1998). Preventing reading difficulties in young children. Washington, DC: National Academy Press.

Soderstrom, M. (2007). Beyond babytalk: re-evaluating the nature and content of speech input to preverbal infants. Developmental Review 27, 50 I-32.

Tamis-LeMonda, C. S., Bornstein, M. H. \& Baumwell, L. (200I). Maternal responsiveness and children's achievement of language milestones. Child Development 72, 748-67.

Tomasello, M. \& Farrar, M. J. (1986). Joint attention and early language. Child Development 57, I $454-63$.

Weisleder, A. \& Fernald, A. (2013). Talking to children matters: early language experience strengthens processing and builds vocabulary. Psychological Science 24, 2143-52.

Weizman, Z. O. \& Snow, C. E. (200I). Lexical input as related to children's vocabulary acquisition: effects of sophisticated exposure and support for meaning. Developmental Psychology 37, 265-79. 